\title{
The power of the family
}

\author{
Alberto Alesina • Paola Giuliano
}

Published online: 27 May 2010

(c) The Author(s) 2010. This article is published with open access at Springerlink.com

\begin{abstract}
We study the importance of family ties on economic behavior. We define our measure of family ties using individual responses from the World Value Survey (WVS) regarding the role of the family and the love and respect that children are expected to have for their parents in 81 countries. We show that with strong family ties home production is higher and families larger, labor force participation of women and youngsters, and geographical mobility lower. To assess causality, we look at the behavior of second generation immigrants. Our results overall indicate a significant influence of the strength of family ties on economic outcomes.
\end{abstract}

Keywords Family ties · Culture $\cdot$ Immigrants

JEL Classification $\mathrm{Z} 10 \cdot \mathrm{Z} 13$

\section{Introduction}

The strength of family ties varies across cultures and it matters for economic decisions. In this paper we document that the strength of family ties determines, via the organization of the family, the amount of home production, the division of labor of men and women between market activities and home activities, and the participation of women in the labor force as a

\author{
A. Alesina \\ Harvard University, Cambridge, MA, USA \\ A. Alesina \\ IGIER, Bocconi University, Milan, Italy \\ P. Giuliano $(\square)$ \\ UCLA Anderson School of Management, Los Angeles, CA, USA
}


result. ${ }^{1}$ Strong family ties require a member of the family (typically the wife) to stay more at home to "run" the family organization, the role of women is therefore more "traditional" (by this term we identify the view of "stay at home" wives and mothers.) Also strong family ties imply geographical proximity of adult children: young adults stay home longer with strong family ties and when they exit the parental household they tend to stay close to enjoy the benefits of the family, both emotional and practical (grandparents services as baby sitters for instance). Geographical mobility is important because it influences the quality of matches between jobs and applicants; it also influences investment in human capital, related to the type of activities available in a certain area. If youngsters stay close to home the match between talented ones and top universities is imperfect. Also, differences in living arrangements, geographical mobility and family structures can have major macroeconomic and demographic consequences. Staying at home for a long period of time can have important implications for household formation, fertility and consumption (Giuliano 2007, 2010 shows that the particular family structure and the long permanence of young adults in their parents place could account for the dramatic reduction in fertility in Southern Europe. Bentolila and Ichino (2008) find that consumption losses associated with unemployment shocks are much lower in Mediterranean societies where young adults live with their parents and the family provides insurance). Similarly, differences in geographical mobility are closely related to unemployment and job mobility. ${ }^{2}$

We construct our cultural measure of family ties using individual responses, taken from the World Value Survey (WVS), on the role of the family and the love and respect that children are expected to have for their parents in over 80 countries. As a first step we document that there are systematic correlations between the strength of family ties, living arrangements, geographical mobility, household division of roles inside the household and female and youth labor force participation. In addition, we shed some light on a causal interpretation of these findings, showing that the same pattern tends to persist among second-generation immigrants in the US and other countries. Our results are robust to the inclusion of a large set of controls and to different estimation strategies.

Our paper is related to a recent literature that has investigated the importance of culture for economic outcomes, the transmission of cultural traits across generations and their interaction with institutions. ${ }^{3}$ We contribute to this literature by emphasizing the importance of family values as one of the most relevant cultural traits, able to explain important aspects of the organization of a society.

The idea that the nature of family ties influences economic behavior and thus economic development is not new. An early proponent of this view was Banfield (1958) who examined the extreme and pathological case of a small village in Southern Italy. Using that example he argued that in a society where people are raised to trust only their family networks, they are also taught to distrust people outside the family, therefore not contributing to the accumulation of social capital, which in turn impedes the development of formal institutions and economic cooperation. A large strand of literature in sociology and political science has also emphasized the importance of the family as the micro-foundation of society, parallel to

\footnotetext{
1 What people do when they do not work in the market is a topic that has received much empirical attention recently in the context of a discussion of a decline in hours worked in the market in some European countries relative to the US (see Prescott 2004; Blanchard 2001; Alesina et al. 2005 for instance). Hammermesh and Weil (2006) show that men and women work exactly the same amount with variable shares of market versus non market activities in different countries.

2 See Bartel (1979), Blanchard and Katz (1992), DaVanzo (1978) and Pissarides and Wadsworth (1989).

3 See Algan and Cahuc (2007, 2010), Fernandez and Fogli (2009), Giuliano (2007), Guiso et al. (2006), Luttmer and Singhal (2008) and Tabellini (2008, 2010) amongst many others.
} 
the state and the market, and able to systematically pattern people's behavior, expectations and incentives. Focusing on Western Europe, Reher (1998) divides countries between "weak family ties" (the Scandinavian European countries) and "strong family ties societies" (the Mediterranean group). According to this author the "strength and weakness refers to cultural patterns of family loyalties, allegiances, and authorities which are reflected in demographic patterns of coresidence with adult children and older family members and to organizing support for the latter". Differences in cultural norms to respect to the strength of family ties would then immediately be reflected in a particular family structure with lower levels of geographical mobility, younger and older people who tend to gravitate around the family nest and larger family size as a result of that.

Strong family ties societies (Esping-Andersen 1999; Ferrera 1996; Castles 1995; Korpi 2000) are also characterized by the existence of family solidarity and an unequal division of family work between men and women (what has been called the "male-breadwinner hypothesis"): ${ }^{4}$ weak family ties will foster an egalitarian gender role in which men and women participate equally in employment and housework, whereas strong family ties are based on the "male-breadwinner hypothesis" in which the man works full-time and the woman dedicates herself to housework. In the more traditional-strong family ties societies is the woman who is supposed to fulfill the family obligations and as such participate less in the market. According to this literature, societies fostering strong family ties should be characterized by the permanence of traditional family structures, by a network of intergenerational exchange based on solidarity and by an unequal division of family labor where the male is the primary economic provider and the woman stays at home. ${ }^{5}$

This paper is organized as follows. Section 2 presents evidence on within country differences using evidence drawn from close to 80 countries. Section 3 focuses on second generation immigrants in the US. Section 4 discusses robustness checks. Section 5 concludes.

\section{Within country evidence}

\subsection{Data}

\subsubsection{Data description}

We use four waves of the WVS and the Multinational Time Use Study for the within country evidence. The WVS is a compilation of national surveys on values and norms on a wide variety of topics, carried out four times (1981-1984, 1990-1993, 1995-1997 and 1999-2004.) The coverage varies depending on the wave, starting with 22 countries in 1980 and reaching 81 countries in the fourth wave. The questionnaires contain information on different types of attitudes, religion and preferences, as well as information on

\footnotetext{
4 These comparative studies show also that an institution of the family with strong ties, specific living arrangements and gender relations (Korpi 2000) has also been fundamental in explaining the evolution of welfare states regimes in post-industrial economies. In Southern Europe, a culture based on strong family ties, where the family provides for everyone and the woman stays at home, the provision of services to children and the elderly has been privatized. In the case of the social democratic welfare regime (such as the Scandinavian countries), the state has been trusted to provide services to children and the elderly; whereas in the liberal regime is the market that provides for those. The evolution of the welfare state related to family arrangements is not the goal of this paper.

${ }^{5}$ According to Esping-Andersen, the persistence of this model, has also been helped by a welfare state model that has historically delegated family care services for children and the elderly to the family sphere and has protected the male breadwinner figure.
} 
standard demographic characteristics (gender, age, education, labor market status, income, etc.). Our sample consists of 81 countries with a broad variety of income levels, religions and geography.

The Multinational Time Use Study is a cross-nationally harmonized set of time use surveys composed of identically recorded variables. Each case in the dataset corresponds to one diary day. Only records with complete diaries (expressed in minutes and that added up to $24 \mathrm{~h}$ ) are included. Diaries with more than $60 \mathrm{~min}$ of unclassified or missing time are excluded. The sample of countries is however small: 12 countries covered for the 1990s. Descriptive statistics for all our outcomes of interest of both surveys are found in the Web Appendix.

\subsubsection{A measure of family ties}

We measure the strength of family ties by looking at three WVS variables capturing beliefs on the importance of the family in an individual's life, the duties and responsibilities of parents and children and the love and respect for one's own parents. The first question assesses how important the family is in one person's life and can take values from 1 to 4 (with four being very important and 1 not important at all). The second question asks whether the respondent agrees with one of two statements (taking the values of 1 and 2 respectively): (1) One does not have the duty to respect and love parents who have not earned it; (2) Regardless of what the qualities and faults of one's parents are, one must always love and respect them. The third question prompts respondents to agree with one of the following statements (again taking the values of 1 or 2 respectively): (1) Parents have a life of their own and should not be asked to sacrifice their own well being for the sake of their children. (2) It is the parents' duty to do their best for their children even at the expense of their own wellbeing.

We combine these measures in two ways. First we take the sum of all of them; a higher number corresponds to stronger family ties. Second, we extract the first principal component from the whole dataset with all individual responses for the original variables. Table 1 displays the correlation at the country level between the three original cultural variables, their sum and the first principal component. All the variables are highly and positively correlated amongst each other. Note also that the principal component is almost perfectly correlated with the sum of the three variables, indicating that the principal component assigns very similar weight to all the variables. Given the very high correlation between the sum and the principal component we will use as main cultural variable the first principal component.

Figure 1 displays the values of our measure of the strength of family ties (expressed using the first principal component) at the country level. The ranking of the different countries is broadly consistent with perceptions and insights from the sociological and political science literature. Northern European countries, Germany, Netherlands and many Eastern European countries have weak family ties, while African, Asian and Latin American countries lie in the highest range. Among the OECD, we find that Turkey, Poland, United States, Korea and the Southern European countries (with the exception of Greece) are among the countries with the strongest ties, while as before Northern Europe, Netherlands and Germany are the group with the weakest ties. The analysis that follows, however, will use only within countryevidence. 
Table 1 Correlations among family values

$\begin{array}{lllll}\begin{array}{l}\text { Family } \\ \text { important }\end{array} & \text { Parental duties } & \begin{array}{l}\text { Respect } \\ \text { and love } \\ \text { parents }\end{array} & \begin{array}{l}\text { Principal } \\ \text { component }\end{array} & \text { Sum } \\ & & & & \\ \end{array}$

\begin{tabular}{|c|c|c|c|c|c|}
\hline Family important & 1.0000 & & & & \\
\hline Parental duties & 0.5657 & 1.0000 & & & \\
\hline Respect and love parents & 0.3641 & 0.5667 & 1.0000 & & \\
\hline Strong family ties (princ. comp.) & 0.6697 & 0.8683 & 0.8667 & 1 & \\
\hline Sum & 0.7050 & 0.9106 & 0.8054 & 0.9934 & 1 \\
\hline
\end{tabular}

Correlations are calculated at the country level

The variable Strong family ties is constructed by taking the first principal component of the following three variables:

1. Family important it assesses how important is the family in one person's life and can take values from 4 (very important) to 1 (not important at all)

2. Parental duties the respondent agrees with one of the two statements: Regardless of what the qualities and faults of one's parents are, one must always love and respect them (taking the value of 2) and one does not have the duty to respect and love parents who have not earned it (taking the value of 1)

3. Respect and love parents the respondent agrees with one of the two statements: It is the parents' duty to do their best for their children even at the expense of their own well-being (taking the value of 2) and parents have a life of their own and should not be asked to sacrifice their own well being for the sake of their children (taking the value of 1)
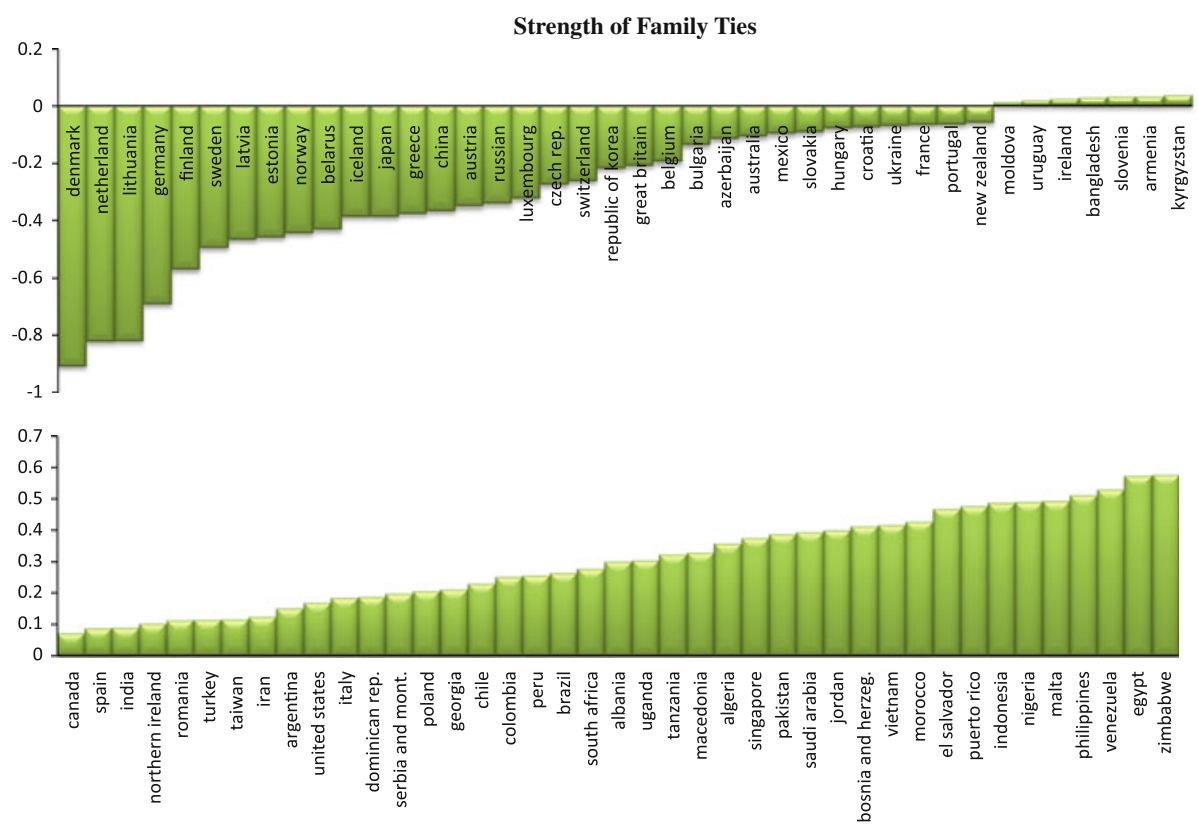

Fig. 1 Strength of family ties

\subsection{Specification}

The strength of family ties differs widely across countries. By comparing outcomes across countries we would have problems of omitted variables. We therefore perform a 
within-country analysis. The inclusion of country fixed effects allows us to hold constant all institutional features (like labor market institutions) and macro variables which are the same for the entire country. These results, however, would constitute a lower bound of the importance of family ties on economic outcomes to the extent that the importance of family ties has been absorbed in the national culture, as captured by country fixed effects. Note that, despite the inclusion of country fixed effects, there is still heterogeneity in family values within individuals in the same country and these differences may persist. Bisin and Verdier (2000, 2001), Bisin et al. (2004) and Tabellini (2008) provide a plausible explanation for this heterogeneity. According to these authors, cultural values are passed down from parents, who optimally choose them, to kids; and these norms tend to persist from generation to generation. Heterogeneity in parents preferences and experiences may then result in heterogeneity in instilled values about the strength of family ties.

For our within-country empirical analysis, we run a series of regressions of the following type:

$$
Y_{i j t}=\beta_{0}+\beta_{1} S F T_{i j t}+\beta_{2} X_{i j t}+\gamma_{j}+\delta_{t}+\gamma_{j} \delta_{t}+\epsilon_{i j t}
$$

where the left hand side variable $Y_{i j t}$ represents the realization of a certain variable for individual $i$ in country $j$ at time $t$. We use either probit or OLS depending on the nature of $Y_{i j t}$. $S F T_{i j t}$ is our variable of interest defined as "strength of family ties". $X_{i j t}$ are our controls which vary depending on the left hand side variable. Our choice of controls is standard and follows the relevant literature. All the regressions include country fixed effects $\left(\gamma_{j}\right)$, wave fixed effects $\left(\delta_{t}\right)$ and their interactions $\left(\gamma_{j} \delta_{t}\right)$. Note that all our results in this part can be interpreted as mere correlations, whenever we use the word "impact" or "effect" of family ties on attitudes and outcomes it is only to simplify the exposition. We will turn to causality in the next section.

\subsection{Results}

\subsubsection{Youth and female labor force participation}

Table 2 reports the results for youth and female labor force participation (columns 1 and 2). Each regression controls for country fixed effects, wave fixed effects and their interactions, and several individual characteristics, including a quadratic for age, a dummy for being male, dummies for the level of education, income and religious denomination (the results for the full specification are reported in the Web Appendix). The controls for religious denomination are important because religious beliefs influence the role of women in society, their labor force participation and also the other family outcomes in which we are interested in. ${ }^{6}$ The coefficient on the strength of family ties is significant with the expected sign, implying less labor force participation of women and youth with strong family ties. The reported coefficients are the effect of a marginal change in the corresponding regressor on the probability of being part of the labor force. An increase in one standard deviation in the strength of family ties implies an increase in youth labor force participation of 0.0055 (roughly $1 \%$ of the sample mean) To make a comparison with the level of education, an increase in one standard deviation in secondary education implies a reduction of 0.0066 in youth labor force participation (when compared with people with tertiary education), a bit more than $1 \%$ of the

\footnotetext{
6 Dummies on religious denomination have the expected sign (for example, Catholic, Muslim and Hindu tend to believe in a more traditional role of women in society and also have lower female labor participation) consistent with what has been found in the literature (see Guiso et al. 2003).
} 


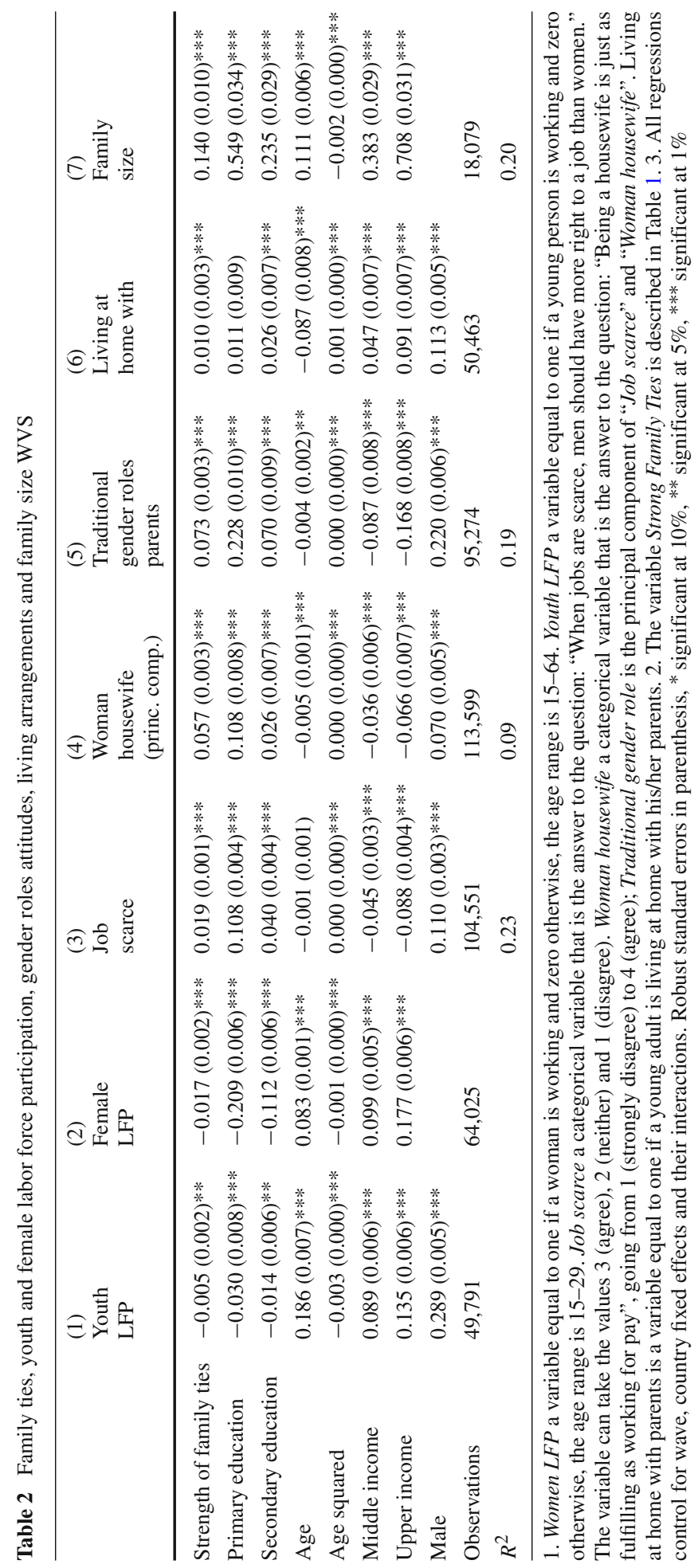


sample mean. The effects of family ties are therefore very similar to the return to education. For female labor force participation, an increase in one standard deviation in the strength of family ties implies a reduction in female labor force participation of roughly 0.02 , which is equivalent to $4 \%$ of the sample mean. For comparison, an increase in one standard deviation for secondary education implies a reduction (compared to tertiary education) in female labor force participation of 0.05 , about $12 \%$ of the sample mean. The coefficients on the other controls are sensible and robust. (They are reported in the Web Appendix.)

\subsubsection{Gender role attitudes and family arrangements}

The nature of family ties could affect the perceived role of women in society. To evaluate the latter we use the following two questions from the WVS: "When jobs are scarce, men should have more right to a job than women." The variable could take the values 3 (agree), 2 (neither) and 1 (disagree). The second question is phrased as follows "Being a housewife is just as fulfilling as working for pay" and it can take values from 4 (agree) to 1 (strongly disagree). A higher number for both variables represents a more traditional role of women in society. We also take the principal component of these two variables as a summary variable for traditional gender roles in the society. Results are reported in Table 2, columns $3-5$. Full results are reported in the on line appendix. Having strong family ties is associated with a more traditional role of women in society: an increase in one standard deviation in the strength of family ties implies an increase in the belief about women as summarized by the variable "job scarce" of 0.02 , which is almost $5 \%$ of the sample mean of this variable. An increase in one standard deviation in secondary education has exactly the same effect.

The last two columns look at two types of family arrangements that should be related to the strength of family ties: the probability of living at home with their parents and family size. As noted above a culture of strong family ties should be reflected in demographic patterns of coresidence with adult children and bigger families. Both variables are positively related to our measure of family ties. An increase in one standard deviation in the strength of family ties implies an increase in living with parents of the order of 0.01 , a $2 \%$ of the sample average. The effect is the same of an increase of one standard deviation in secondary education. An increase in one standard deviation in the strength of family ties implies an increase in family size of the order of 0.15 , which is roughly $5 \%$ of the sample average of this variable (secondary education counts for $3 \%$ ).

The evidence we presented above is likely to be a lower bound of the effects of family ties since fixed effects eliminate all cross country comparisons. In fact, if we replicate the same regressions at the aggregate level the magnitude of the results is substantially larger: an increase in one standard deviation in the strength of family ties implies a decline in female and youth labor force participation of 0.096 and 0.073 (20 and 13\% of the sample average, respectively). The effect for gender role attitudes, staying at home with their parents and family size is equal to $0.13,0.06$ and $0.39(27,12$ and $12 \%$ respectively of the sample averages of these variables). Obviously the size of these coefficients is most likely to be an overestimate of the effects of family ties since many other factors vary across country in addition to family ties. $^{7}$

7 Note that some of the institutional differences across countries may be themselves endogenous to family ties and other related cultural variables. 


\subsubsection{Home production}

Families with strong ties are then associated with more time spent at home by wives/mothers and young adults living at home longer. This implies more home production (in the form of child care, home cooking, caring for the elderly, house cleaning etc.); in addition, according to a more traditional role attributed to women in societies in strong family ties societies, these activities should be mostly performed by wives and daughters.

In Table 3, we regress (OLS) the amount of housework separately for women and men. Housework is defined as the sum of the following activities: washing, hanging and ironing clothes, making beds, any form of house cleaning, other manual domestic work, and putting shops away. ${ }^{8}$ Controls included in the regression are age, age squared, education, marital and employment status, several cross-country characteristics (described below) and our measure of strong family ties. In order to run this regression, we merged the individual data on home production coming from the Time Use Survey with our measure of family ties aggregated at the country level (standard errors are clustered at the country of origin level). As we now have individual data on the time use and country level data on the weakness of family ties, we cannot control for country fixed effects. However, all our regressions control for country characteristics that could drive home production such as per capita GDP and years of education. ${ }^{9}$ In addition we also control for other cross-country differences that could be relevant in the determination of home production. Following Faggio and Nickell (2006) and Jaumotte (2003), we first include a series of tax variables (column 1): the marginal tax rates facing married women at zero hours of work and when they are earning $67 \%$ of average earnings given their spouses are earning $100 \%$ of average earnings, the marginal tax rate facing a single earner. We also control for variables capturing public expenditure on children and parental leave ${ }^{10}$ (column 2), for the strictness of employment protection laws ${ }^{11}$ (column 3) and the average tax wedge ${ }^{12}$ (column 4). Overall, the inclusion of all these variables does not change our results. ${ }^{13}$

The strength of family ties is relevant for the determination of home production of women, but not of men as expected. An increase in one standard deviation in the strength of family ties implies an increase in home production of 11.6 (14\% of the sample average; for comparison, an increase in one standard deviation in secondary education implies a reduction, compared to people with only primary education, in home production of $3.5,4 \%$ of the sample average of home production). The remaining controls in the regressions have the expected sign, married women do more home production, whereas employed women tend to do less. The correlation between education and home production is negative for women, but not for men.

\footnotetext{
8 We do not consider child care as home production since this could be affected by different types of welfare systems. The results however are robust to the inclusion of this activity in the definition of home production. 9 The data for years of schooling are obtained from Barro and Lee (2001).

10 These variables include real expenditure on cash benefits (annual public expenditures in real dollars on family cash benefits per child age $0-14$ divided by 1,000 ); real expenditures on parental leave (annual public expenditure in real dollars on maternity and parental leave per child aged $0-3$ divided by 1,000), real expenditures on family services (annual public expenditures in real dollars on family services per child aged 0-14 divided by 1,000).

11 The employment protection index comes from Faggio and Nickell (2006) and it refers to regular employment.

12 The average tax wedge is the average labor tax rate, the sum of the average payroll, income and consumption tax rates. The data are taken by Faggio and Nickell (2006).

13 Note that we do not have all these additional controls for our sample. The data are available for only eight of our countries.
} 


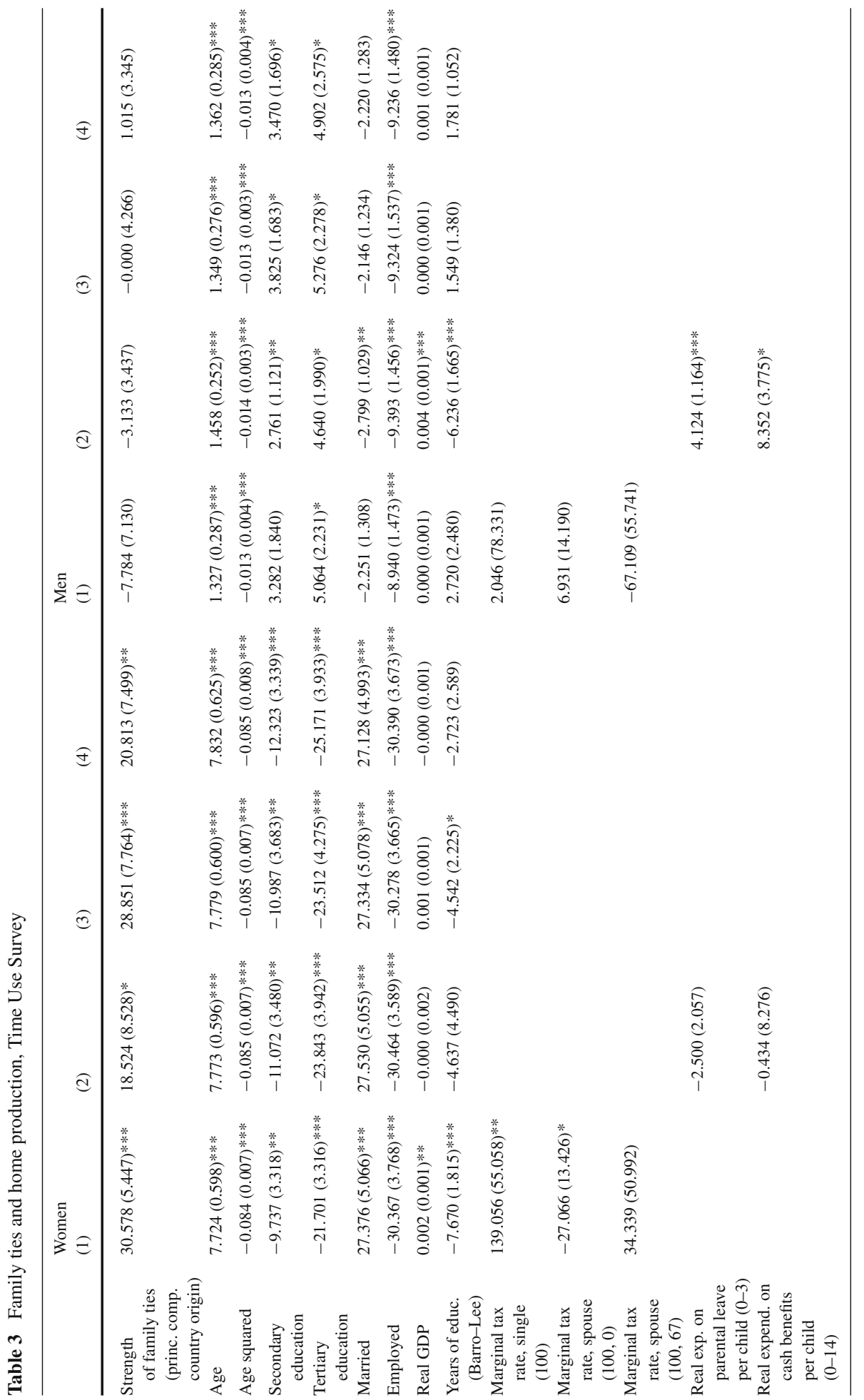




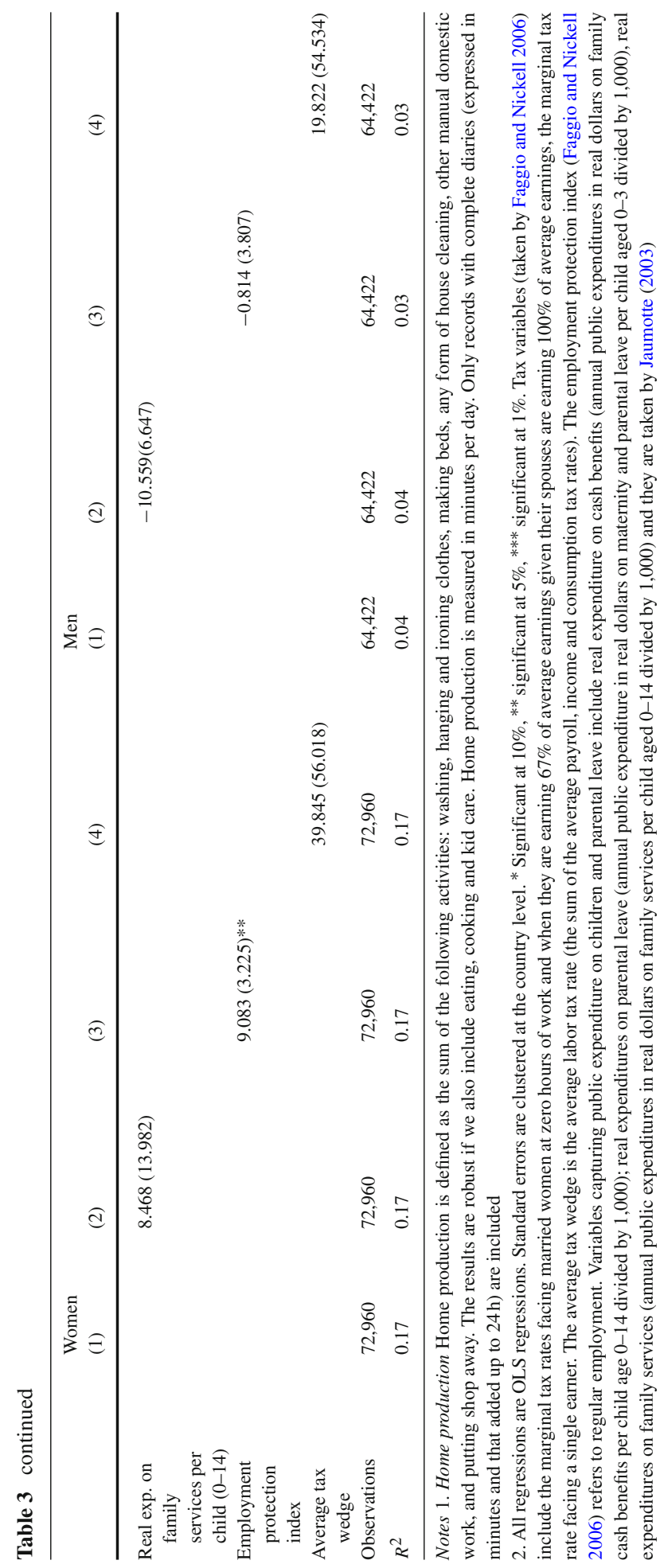




\section{Evidence from second-generation immigrants in the US}

Even though our previous analysis with country fixed effects eliminates confounding effects arising from differences in national institutions, we still have a potential problem of reverse causality. For instance, a woman who does not find work because of bad luck, laziness or any other individual characteristic may spend more time at home and feel (or convince herself) that family is important. To limit this concern, we study the impact of different forms of family ties from the countries of origin on second generation immigrants in the US. ${ }^{14}$ We associate to each immigrant our measure of family ties defined as the average set of beliefs regarding family ties in the country of origin. ${ }^{15}$ In other words, we assign to each immigrant a sort of "cultural baggage" that he/she brings with him/herself to the US and transmits to the second generation. ${ }^{16}$ Thus the beliefs attributed to any immigrant are those of the country of origin, not those that he/she expresses and that therefore could be caused by his/her special circumstances. We therefore eliminate the problem of a possible causation from individual characteristics and economic behavior (for instance labor force participation) to beliefs, since the latter are determined in the country of origin of the second generation immigrants.

\subsection{Data}

Our main datasets are the March Supplement of the Current Population Survey (CPS) and the American Time Use Survey (ATUS). The March Supplement of the CPS is the only recent available dataset in which individuals were asked (starting from 1994) about their parents' country of origin. ${ }^{17}$ We define second generation immigrants by looking at the country of origin of the father respondent in order to maximize the number of observations. The CPS also reports the country of origin of the mother, but the sample size is substantially smaller, due to a much higher number of missing observations. ${ }^{18}$ We pool fifteen years of data to have a higher number of observations. We use the CPS to study the following outcomes: female

\footnotetext{
14 The use of immigrants (first or second generation) to study the importance of culture on economic behavior is becoming relatively standard in the analysis of culture (see Antecol 2000; Carroll et al. 1994; Fernandez and Fogli 2009; Giuliano 2007 amongst others).

15 Note that our sample mainly consists of individuals between 15 and 29 year old, which means that, since we are considering data from the 1994 to 2008 of the CPS, they are born sometime between 1965 and 1990 , so their fathers arrived in the US before that time. Ideally we would like to associate to those individuals the cultural values of their father's countries of origin for the period of their arrivals in the US. Unfortunately, data on beliefs that go so far back in time do not exist. The only thing we can do, given data availability, is to associate to those immigrants the values that people from their father's country of origin hold today. This is a limitation, but not so dramatic, for several reasons. First, as emphasized before, several recent studies found that cultural differences between nations remained quite stable over time (Inglehart and Baker 2000), moreover values appear pretty stable even for those countries experiencing dramatic economic changes (see Schwartz et al. 2000 for the case of Central and Eastern Europe). The assumption that culture evolves slowly over time is standard in the literature (see Tabellini 2008, 2010) Moreover, at least for the period between 1980 and 2000, Bertrand and Schoar (2006) found that norms on family values have been pretty stable over time and show little adjustment to economic conditions.

16 As emphasized by Bisin and Verdier (2001), Bisin et al. (2004) and Benabou and Tirole (2006) beliefs are partially determined by the actual environment and partially inherited from previous generations, what we called "culture". With the immigrant exercise we try to isolate this cultural component.

17 The Census reports the information about the father's country of origin until 1970.

18 Using the country of origin of the father to define second generation immigrants is fairly standard in the literature (see Card et al. 1998).
} 
and youth labor force participation, geographical mobility, living arrangements, as measured by the probability of living as young adult in one's parents place, and family size.

The ATUS is a time survey on time use in the United States. The goal of the survey is to measure how people divide their time among life's activities. The individuals chosen for participation in the ATUS are selected randomly from households that are completing their participation in the CPS. As a result, the survey contains information on the country of origin of the respondent and his/her parents and this allows us to identify second generation immigrants. The sample is however much smaller as the survey is available only for five years (from 2003 to 2008). Individuals report all the activities done over a 24-h period from 4:00 a.m. to 4:00 a.m. on an assigned diary day. Home production is defined as the set of household activities including housework, cooking, yard care, pet care, vehicle maintenance and repair, and home maintenance, repair decoration and renovation. Household management and organizational activities - such as filling out paperwork, or planning a party- are also included in this category. In the appendix we also report as a robustness check a regression for a definition of home production which also includes caring for and helping household members. This category captures activities the respondent did to care for or help any child or adult in the respondent's household, regardless of relationship, age, or physical or mental health status.

\subsection{Specification}

For consistency with the regressions of the previous section, we run the following model in OLS or probit depending on the nature of the left hand side variable:

$$
Y_{i k s}=\alpha_{0}+\alpha_{1} S F T_{k}+\alpha_{2} X_{i}+\delta_{s}+\varepsilon_{i k s}
$$

where $Y_{i k s}$ is the left hand side of interest for individual $i$, living in state $s$ and whose father comes from country $k . X_{i}$ includes a series of individual controls which vary depending on the outcome of interest and are standard in the literature, $S F T_{k}$ is our measure of the strength of family ties which varies by immigrant's country of origin and $\delta_{s}$ is a full set of state dummies. To better control for the possibility that immigrants coming from different countries select in different areas we also run a specification where we include county dummies. Standard errors are clustered at the country of origin level.

\subsection{Results}

\subsubsection{Youth and female labor force participation}

Tables 4 and 5 present our results for female and youth labor force participation (the sample includes women 15-64 years old and young adults between the ages of 15 and 29, respectively). To be consistent with the previous section we define a dummy equal to one if person $i$ is in the labor force (labor force participation is defined by looking at the number of hours worked last week or weeks worked last year, the dummy is equal to 1 with positive hours/weeks worked. ${ }^{19}$ ) Our main specification (standard in the literature) is reported in column 1 , where we control for a quadratic for age, education, ${ }^{20}$ marital status, income and state fixed effects. We use a dummy for participation rather than hours worked to keep the

19 The results with hours worked or weeks worked are the same.

20 We include two dummies, one for people with up to 12 years of schooling and one for people with some college. The excluded group is given by people with completed college and more. 


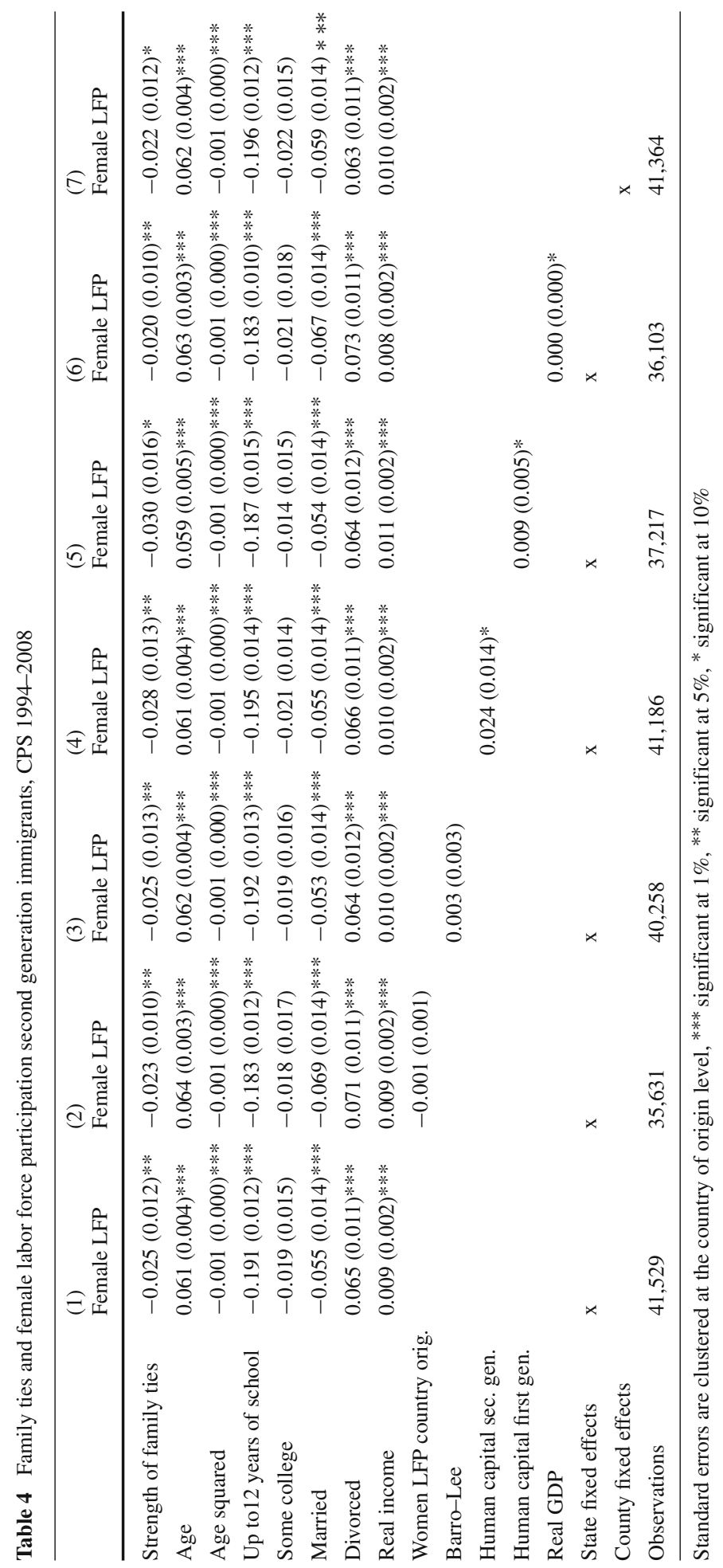




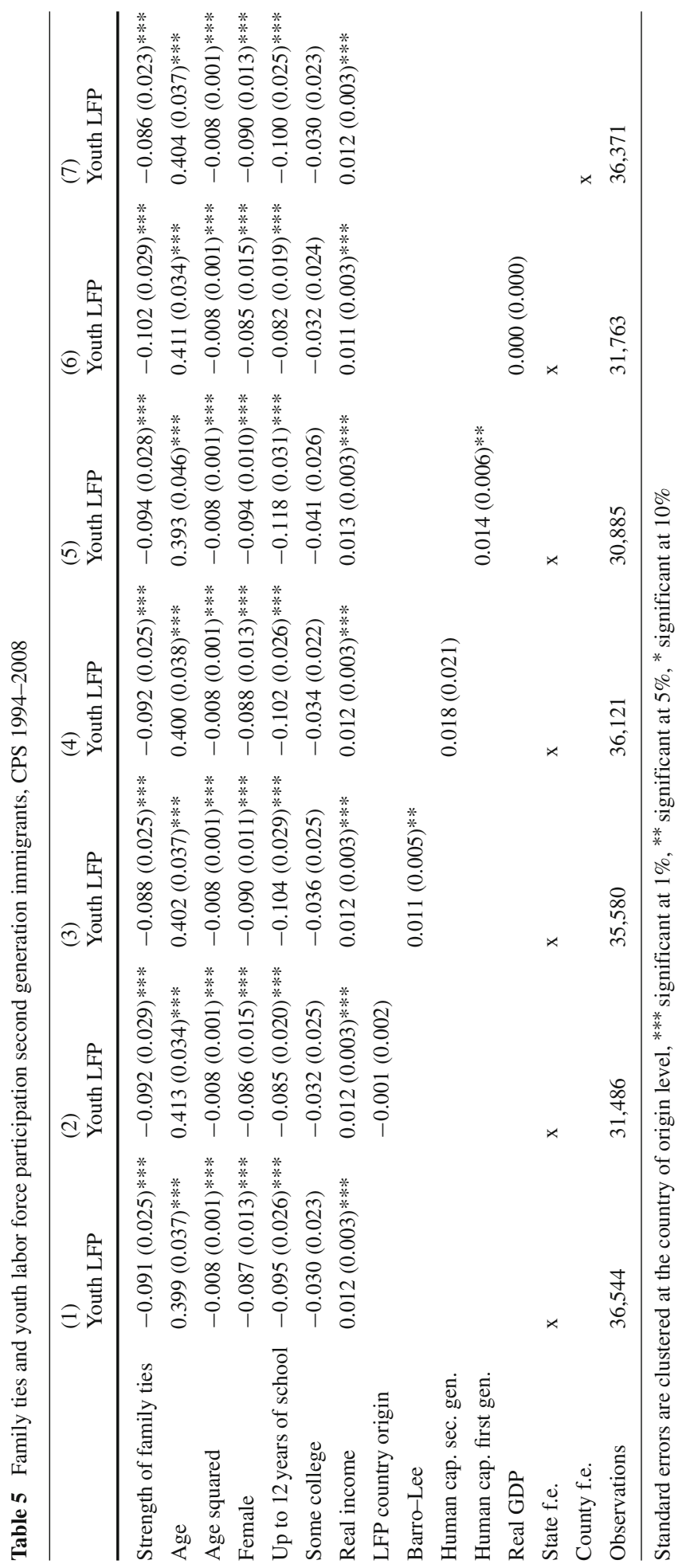


analogy with our previous section where we did not have data on hours worked. The other columns in the tables contain robustness checks (described below).

Women and young adults coming from strong family ties societies participate less in the labor market. An increase in one standard deviation in the strength of family ties implies a reduction of female labor force participation of 0.01 ( $1.5 \%$ of the sample average; for comparison having some college as opposed to college and more has the same effect). An increase in one standard deviation in the strength of family ties implies a reduction in youth labor force participation of 0.02 (roughly $5 \%$ of the sample average, the effect is twice the size of an increase in one standard deviation for having some college, which has an impact equal to $2.2 \%$ of the sample average).

\subsubsection{Youth geographical mobility, living arrangements and family size}

In Tables 6 and 7 (as before column 1 reports the main specification and the remaining columns all the robustness checks), we regress our measure of geographical mobility (a dummy equal to 1 if the person moved within states, between states or abroad) and the probability of living at home with their parents, respectively, on a quadratic for age, a female dummy, marital status, a dummy for being unemployed, family income and state fixed effects. The variable on the strength of family ties is always significant and with the expected sign; youth belonging to immigrant groups coming from strong family ties societies tend to migrate less and stay more with their parents. This is also consistent with Giuliano (2007), who uses as proxies for culture both country dummies and measures of living arrangements in the country of origin. Her sample is limited to only European countries: here we extend our analysis to youth coming from all the regions of the world. All the controls have the expected sign. Interestingly enough, more men than women live at home: perhaps women are less satisfied than men living at home given the gender roles in family with strong ties documented above. Also women marry younger than men. An increase in one standard deviation in the strength of family ties implies a reduction in geographical mobility of 0.01 (6\% of the sample average), the effect is about one third of the effect of having some college. An increase in one standard deviation in the strength of family ties implies an increase in the probability of living at home of 0.015 (which is equivalent to $4 \%$ of the sample average; the effect is half the magnitude of the impact of one standard deviation in the education variable corresponding to some college).

Consistently with the within country analysis families are larger for immigrants coming from strong family ties societies (Table 8 ). The variable family size counts the number of own family members residing with each individual. An increase in one standard deviation in the strength of family ties implies an increase in family size by 0.03 ( $2 \%$ of the sample average; the effect is about $1 / 5$ of the impact of having some college on family size).

\subsubsection{Home production}

We finally check whether second generation immigrants (women in particular) coming from strong family ties societies work more at home in the US as well. Once again we associate to each immigrant the strength of family ties from the country of origin. We run two regressions, one with the standard definition of home production (as described above) and one where we also include time devoted to take care of and help family members (the results for this last specification are reported in the Web Appendix). We split the sample between women and men, as according to the male-bread winner hypothesis women are the one supposed to be 


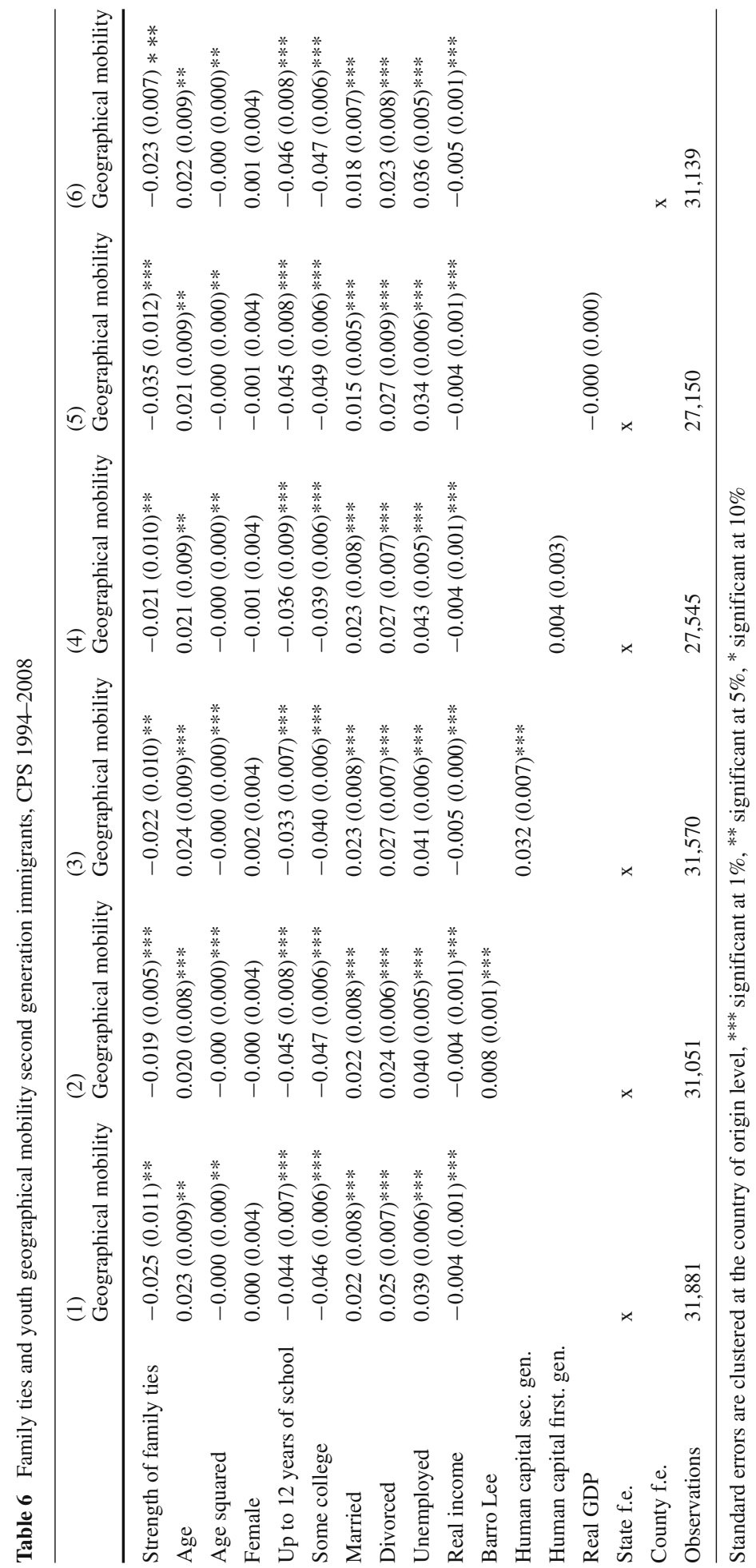




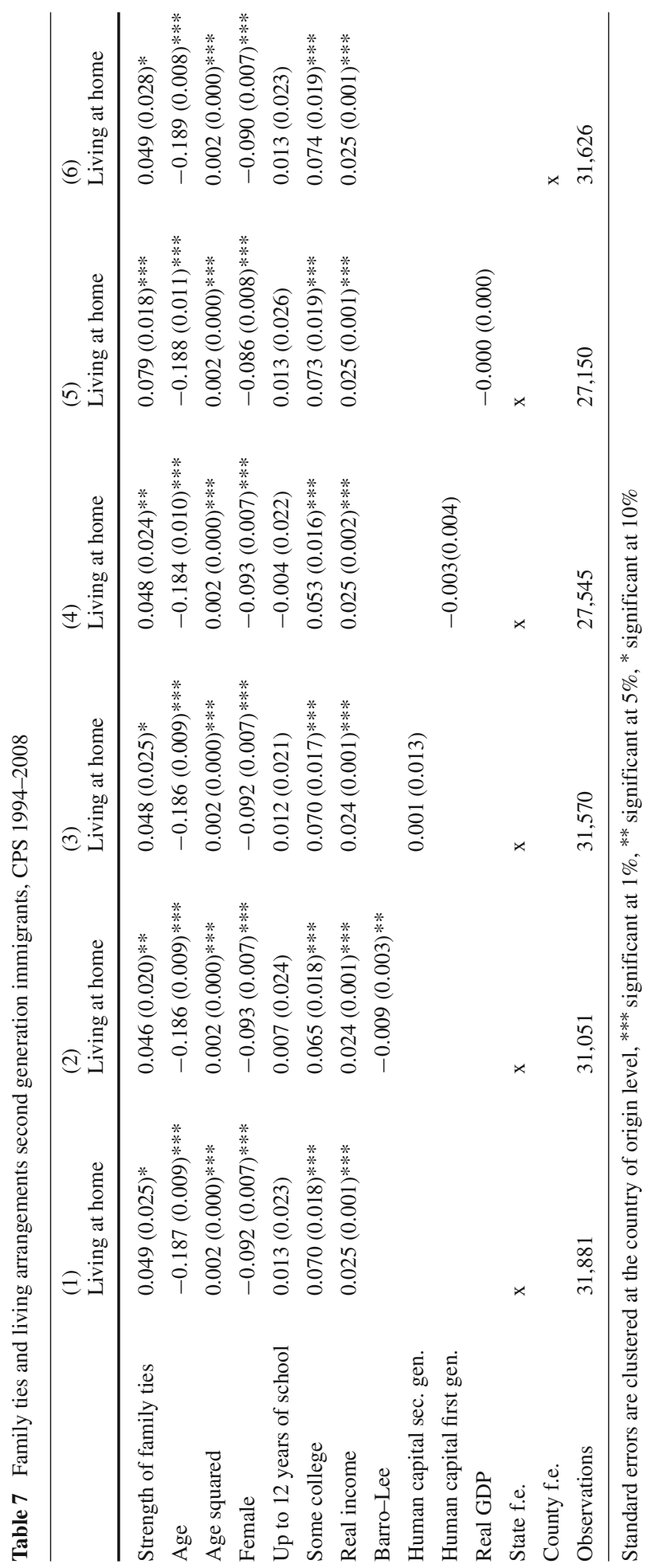




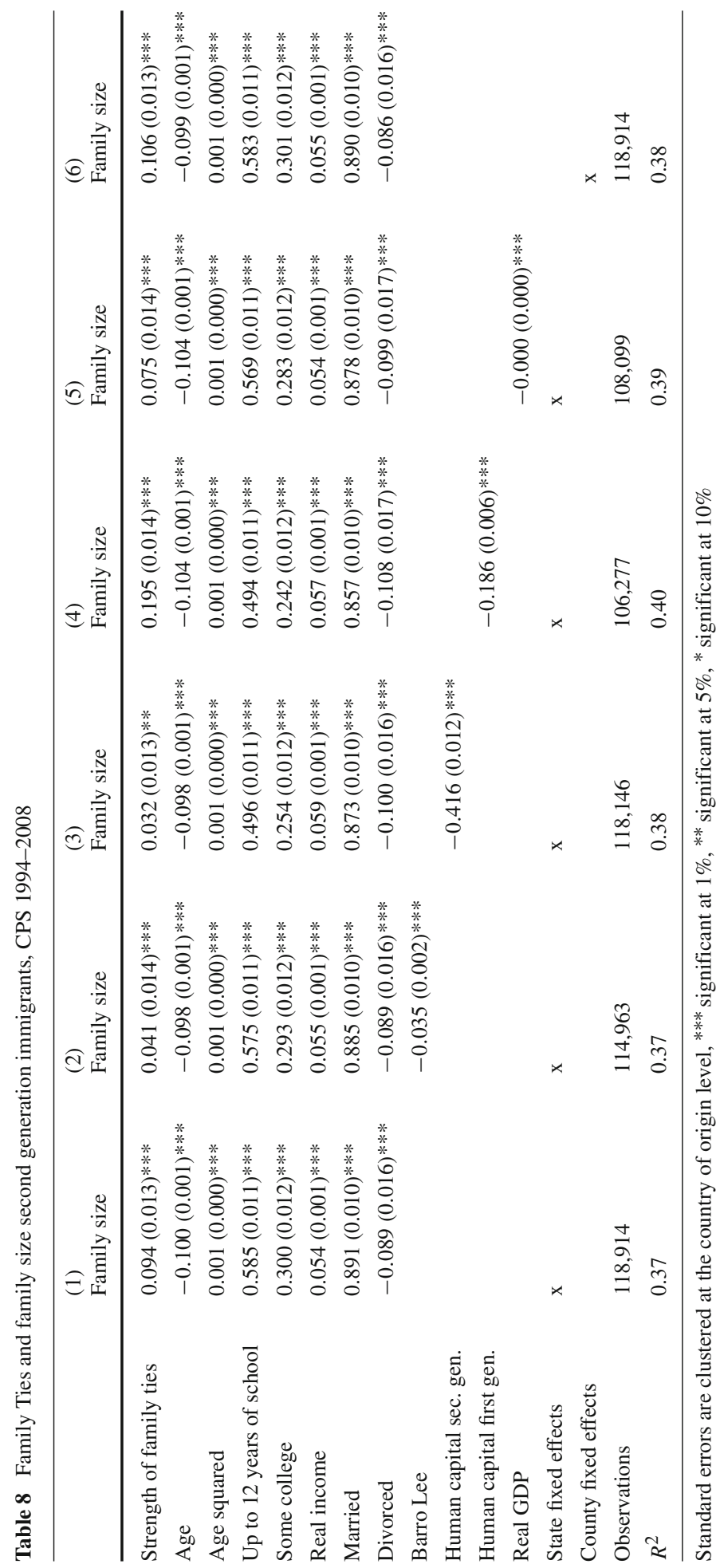




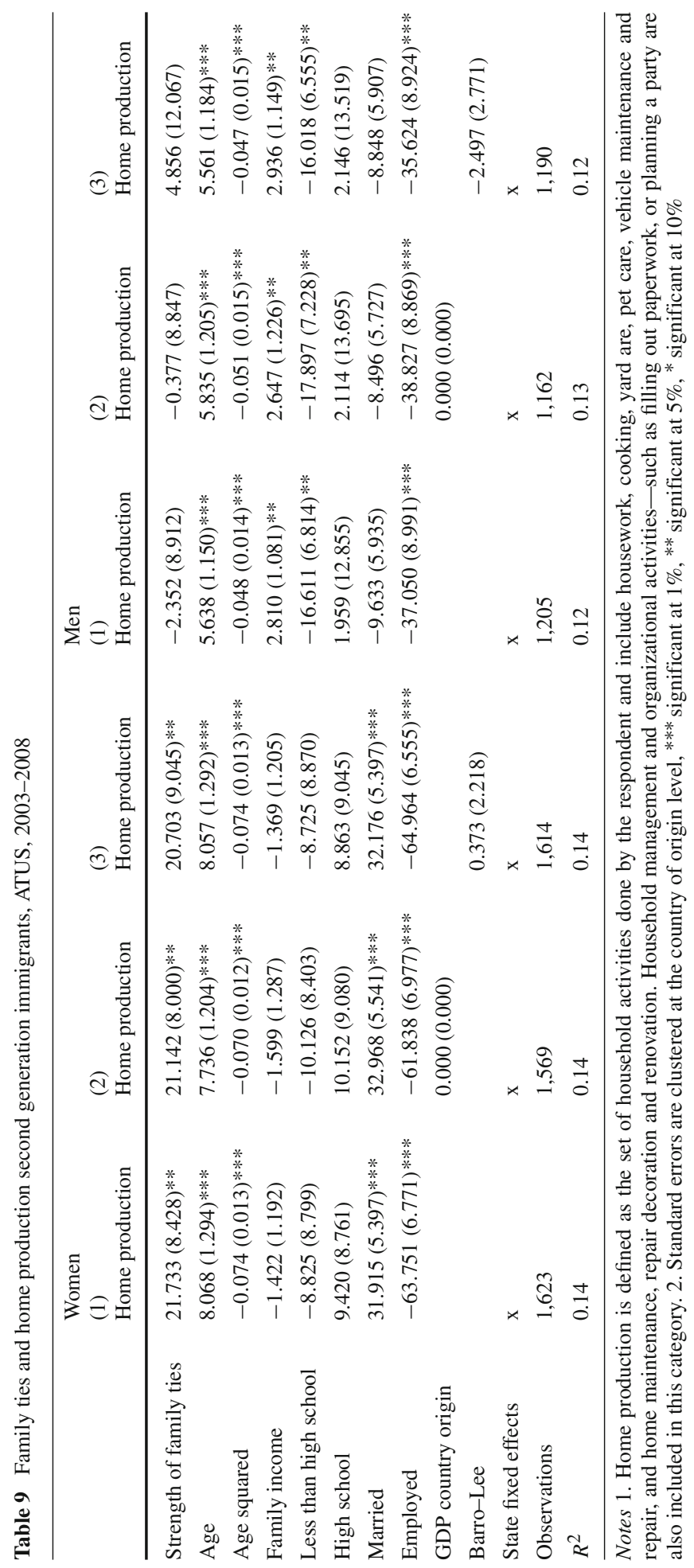


working at home. Note that the number of observations for the regressions on home production is very small. Despite this, we do find results similar to the within country analysis. Women from strong family ties societies perform more housework activities: an increase in one standard deviation in the strength of family ties implies an increase in home production of 7.1 , which is equivalent to $5 \%$ of the sample average of the home production variable. The effect is half of the effect of being married and one fourth of the effect of being employed.

\section{Robustness checks}

\subsection{Omitted variables}

In this section we test the robustness of our results to the inclusion of some possible variables that could drive our results. Previous papers (Antecol 2000; Fernandez and Fogli 2009; Giuliano 2007) regress a specific economic outcome of second generation immigrants (for example female labor force participation) on the same economic outcome in the immigrants' country of origin (i.e. the average level of female labor force participation of the country of origin), which is considered as a summary of the economic, institutional and cultural conditions in the country of origin. This approach was based upon the idea that if country of origin variables mattered in the new environment (the destination country) the effect had to go through the cultural baggage of the immigrant. We do the same thing here. As a first robustness check, we test whether the inclusion of this alternative measure of culture reduces the importance of our measure of family ties. Column (2) in all previous tables include as regressors measures of economic outcomes of interests in the country of origin, whenever available. Our measure of family ties remains statistically significant even after including these variables and it appears to capture better the beliefs relevant to determine immigrants' economic outcomes than the variable representing the same economic outcomes in the country of origin.

One important omitted variable related to our outcomes of interest is unobserved human capital. Although we control for the individual level of education, it is possible that our results are driven by a lower level of human capital in the country of origin, lower parental level of education or lower level of human capital in the community in which immigrants live. We start by checking the robustness of our results to the inclusion of the standard Barro-Lee measure of human capital, capturing the number of years of education in the country of origin (the results are reported in columns 3 or 2). Human capital is an important component in many of the immigrants' economic outcomes, however our results do not change with the introduction of this variable although the size of the coefficient on the family size variable is reduced with the introduction of human capital.

We also check the robustness of our results to the inclusion of parental human capital and the average level of "ethnic" human capital of the network to which immigrants belong (the results are reported in columns 4 and 5, or 3 and 4). These are standard controls in the literature of immigrants' assimilation or the role of networks. Borjas $(1992,1995)$ was the first to introduce the concept of "ethnic" human capital defined as the mean level of human capital of the ethnic group of the fathers' country of origin of second generation immigrants, and showed that educational attainment and wages of second generation immigrants in the 1970 Census crucially depend on it. ${ }^{21}$ We calculate this variable from the 1970 Census, because the immigrants who were in the US in this period were very likely to be the fathers of second

21 This control has also been used by Card et al. (1998), Luttmer (2001) and Fernandez and Fogli (2009). 
generation immigrants in our sample. We calculate the average number of years of schooling for men between 15 and 45 years old. Those men should approximately correspond to the fathers of our second generation immigrants. Our results are robust to the inclusion of this variable. In addition, we also construct a measure of the average level of human capital of the second generation ethnic group to which each individual belongs. By including this measure we are able to capture the importance of peers and neighborhood effects for immigrants outcomes (see Borjas 1992, 1995) Even in this case results do not change. Both variables are often significant in explaining immigrants' economic outcomes.

As a last robustness check we also include the level of GDP in the country of origin (columns 6 or 5): one alternative story is that immigrants belonging to strong family ties societies are coming from poorer countries, therefore the outcomes that we observe in the US among second generation immigrants are just the result of the transmission of a lower level of initial income for strong family ties immigrants. We look at the level of GDP in 1970 (which should roughly corresponds to the timing of arrival of the fathers of second generation immigrants in our sample). Our results do not change with the inclusion of this variable.

Finally, we also include, in the last column of the main tables, county fixed effects to better control for all the characteristics of the local community where immigrants live. Our results are also robust to this specification.

\subsection{Second generation immigrants in 27 European countries}

We conclude by examining whether similar results hold when we look at second generation immigrant outcomes in countries other than the US. This test is useful to check whether there is something related to the country of destination that may explain the results on immigrants regarding family ties. Perhaps weak family ties immigrants find it easier to adjust to the US economic environment, even though it is unclear how this would bias our results. Looking at immigrants going to multiple destinations has also the advantage of reducing the problem due to selection, as the form of selection should vary across destination countries. We use data from the European Social Survey, a cross-sectional survey conducted in a large sample of mainly European countries. There are 27 destination countries. ${ }^{22}$ The survey has been conducted three times (in 2002, 2004 and 2006). We use the second and third wave as they contain information about the fathers' country of origin (not present in the first wave), crucial to identify second-generation immigrants. Unfortunately this dataset has a limited number of observations for each immigrant group, therefore the results should be taken with caution.

As before, we associate to each immigrant the measure of family ties constructed from the WVS, i.e. we associate to each immigrant living in one of the 27 countries of the survey the average beliefs of his/her country of origin. Unfortunately there are no questions that allow us to study living arrangements and geographical mobility, but we can look at youth and female labor force participation, and family size. Results are reported in the Web Appendix, where we follow the standard specification but include also country of destination fixed effects. The results still hold for youth labor force participation and family size. The number of observations is much smaller than the CPS, but the fact that even when we take immigrants from 60 countries and we observe them in 27 different countries of destination, we still find that

22 Austria, Belgium, Bulgaria, Switzerland, Cyprus, Czech Republic, Germany, Denmark, Estonia, Spain, Finland, France, Great Britain, Greece, Hungary, Ireland, Iceland, Luxembourg, Netherland, Norway, Poland, Portugal, Sweden, Slovenia, Slovak Republic, Turkey, Ukraine. 
Family ties and economic outcomes. Country dummies from immigrant regressions on family ties

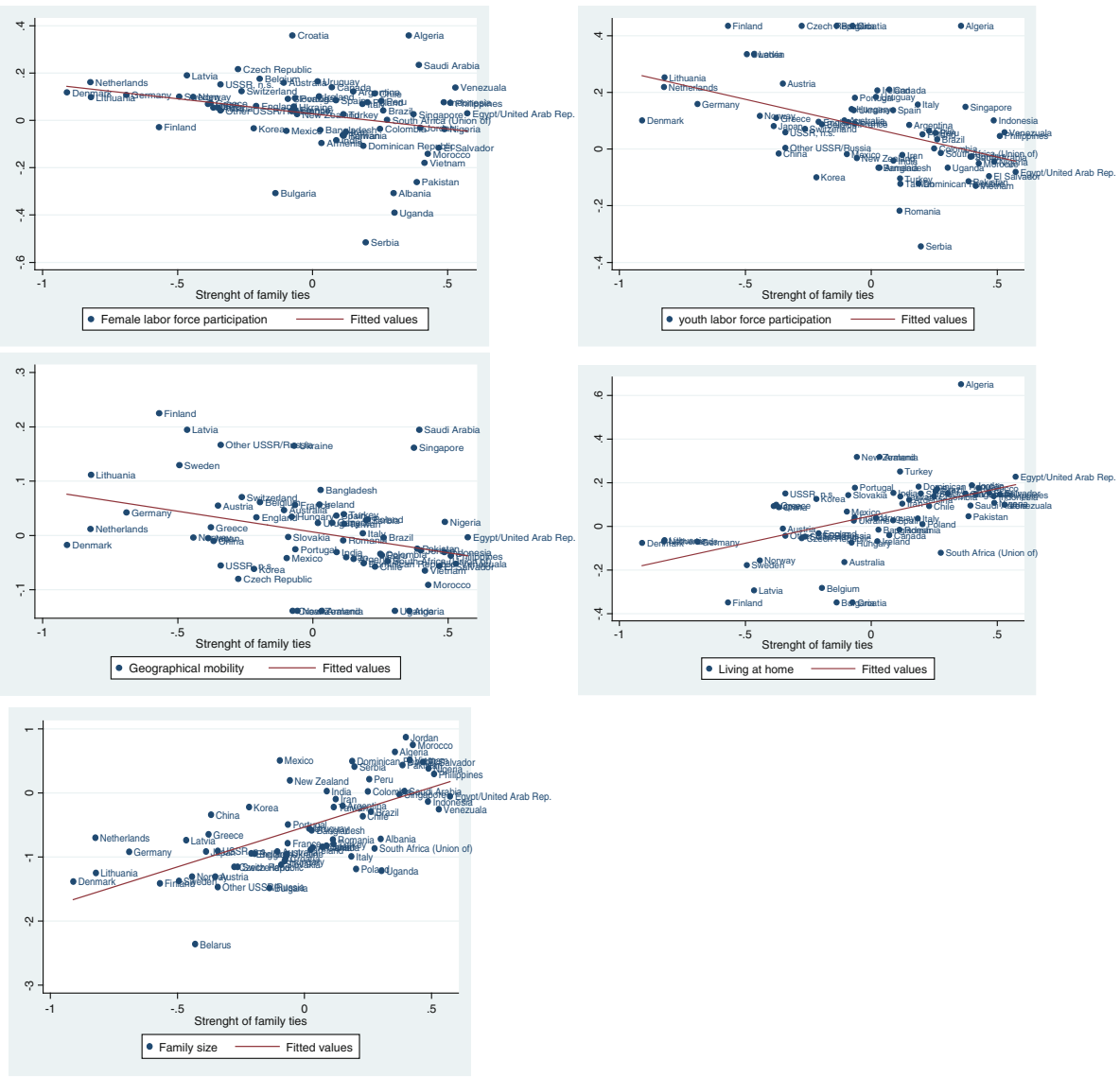

Fig. 2 Family ties and economic outcomes. Country dummies from immigrant regressions on family ties

our measure of family ties is an important determinant of youth labor force participation and family size is encouraging. With all the limitations of this analysis, the results are completely consistent with the findings from the United States.

\subsection{An alternative estimation strategy}

An alternative way of testing the importance of family ties is to run a different specification where in the first-stage we regress immigrants' economic outcomes of interest on country of origin dummies, whereas in the second stage we regress the country dummies coefficients of the various outcomes on family ties and other country of origin variables. With this approach we are first able to estimate an average effect of coming from different countries of origin, and then evaluate the relative importance of our measure of family ties with respect to other country of origin characteristics, including GDP and human capital. The correlations between the country dummies for the different outcomes obtained in the first stage and our measure on the strength of family ties are shown in Fig. 2. The results of the second stage regression, with the inclusion of country controls are reported in the Appendix. The results go in the expected direction, and from the figure it is also apparent that they are not driven 

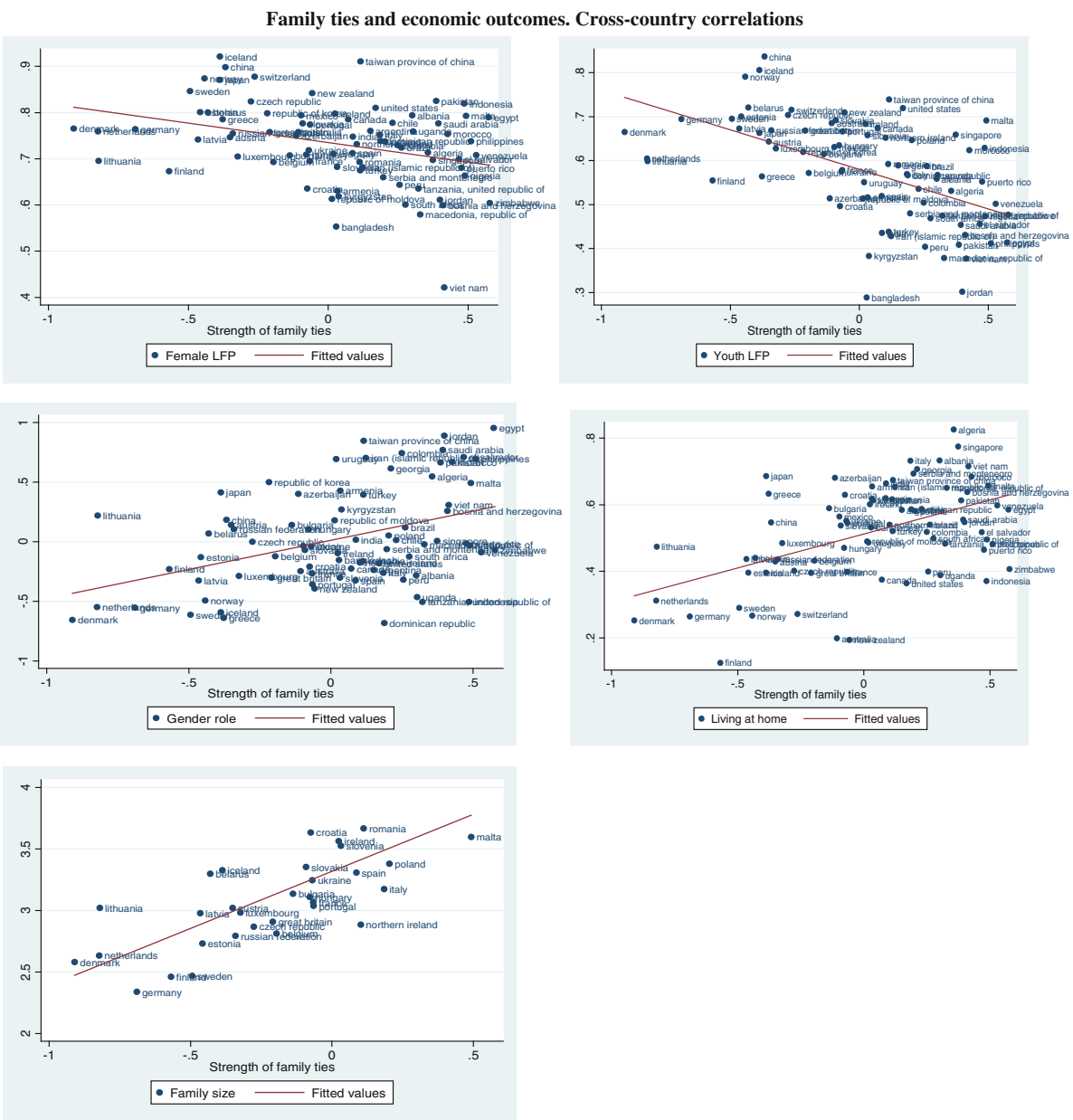

Fig. 3 Family ties and economic outcomes. Cross-country correlations

by few outliers. ${ }^{23}$ Note that the introduction of GDP and human capital does not weaken the correlation between family ties and economic outcomes, with the exception of female labor force participation. A likely explanation is that since women tend to stay home more to take care of the family, they invest less in education to start with.

For comparison with the immigrants' outcomes, we also plot in Fig. 3 the correlations at the country level between economic outcomes and the strength of family ties. It is apparent that immigrants' behavior mimics the behavior in the country of origin, an indication of both the importance and the persistence of the strength of family ties as a relevant cultural trait.

23 To rule out the possibility that our results are driven by one specific immigrant groups, we further check the robustness of our results to the exclusion of second generation Mexicans, the biggest immigrant group in our sample. The results, reported in the Web Appendix, do not change. 


\section{Conclusions}

The family is a key socio economic unit in society and the nature of its organization varies greatly across nationalities. In some cultures/nationalities/regions family ties are weak and members only feel obligated up to a point to be linked to others members of the family. In other cultures family ties are strong. We measure family ties based on answers from the WVS and we show that strong family ties imply more home production of goods and services and less participation in market activities especially for women. This is associated with larger families, a more "traditional" role for women and a higher fraction of young adults living at home. Strong family ties are also associated with less geographical mobility since ties are more useful if people live close to each other. In order to mitigate problems of reverse causation and endogeneity of cultural traits to economic outcomes we use second-generation immigrants in the US. Overall we find an important effect of the nature of family relationships on economic structures. These considerations are important for the design of public polices such as labor laws, welfare provision, education, since the same set of interventions may have very different effects in countries with different family ties.

Acknowledgements We thank Kenneth Chay, Steve Davis, Rafael di Tella, Oded Galor, Ed Glaeser, David Levine, Assar Lindbeck, Marc Rosenzweig, Andrei Shleifer and seminar participants at Boston College, Boston Fed, Boston University, Brown University, Ente Einaudi (Rome), the Haas School of Business, Harvard Business School, the IIES (Stockholm), INSEAD (Paris), Stanford GSB, the University of British Columbia, UCLA-Anderson School of Management, UC San Diego, the NBER Macroeconomics and Individual Decision Making conference and the IZA-SOLETransatlantic Meeting of Labor Economists for useful comments.

Open Access This article is distributed under the terms of the Creative Commons Attribution Noncommercial License which permits any noncommercial use, distribution, and reproduction in any medium, provided the original author(s) and source are credited.

\section{Appendix}

Table A1 World Value Survey, summary statistics

\begin{tabular}{llccll}
\hline Variable & Observations & Mean & SD & Min & Max \\
\hline Youth LFP & 49,791 & 0.546 & 0.498 & 0 & 1 \\
Female LFP & 64,025 & 0.459 & 0.498 & 0 & 1 \\
Job scarce & 104,551 & 0.465 & 0.499 & 0 & 1 \\
Woman housewife & 113,599 & 2.789 & 0.891 & 1 & 4 \\
Gender roles & 95,274 & 0.010 & 1.058 & -2.081 & 1.733 \\
Living at home & 50,463 & 0.498 & 0.500 & 0 & 1 \\
Family size & 17,973 & 3.395 & 1.667 & 1 & 31 \\
Primary & 142,356 & 0.294 & 0.456 & 0 & 1 \\
Secondary & 142,356 & 0.343 & 0.475 & 0 & 1 \\
Age & 142,356 & 41.778 & 16.256 & 15 & 98 \\
Married & 142,356 & 0.658 & 0.474 & 0 & 1 \\
Middle income & 142,356 & 0.371 & 0.483 & 0 & 1 \\
High income & 142,356 & 0.287 & 0.452 & 0 & 1 \\
Male & 142,356 & 0.470 & 0.499 & 0 & 1 \\
\hline
\end{tabular}


Table A2 Multinational Time Use Survey, summary statistics

\begin{tabular}{|c|c|c|c|c|c|}
\hline Variable & Observations & Mean & SD & Min & $\operatorname{Max}$ \\
\hline Age & 145,086 & 32.64 & 9.70 & 15 & 49 \\
\hline Home production & 145,086 & 48.67 & 77.23 & 0 & 900 \\
\hline Employed & 133,950 & 0.69 & 0.46 & 0 & 1 \\
\hline Secondary education & 132,588 & 0.34 & 0.47 & 0 & 1 \\
\hline Tertiary education & 132,588 & 0.29 & 0.45 & 0 & 1 \\
\hline Female & 145,086 & 0.53 & 0.50 & 0 & 1 \\
\hline
\end{tabular}

Countries included in the survey are: Canada, Denmark, France, Netherlands, Norway, United Kingdom, United States, Italy, Germany, Austria, Bulgaria, South Africa

Table A3 March supplement of the CPS, 1994-2008, summary statistics

\begin{tabular}{|c|c|c|c|c|c|}
\hline Variable & Observations & Mean & SD & Min & Max \\
\hline Female LFP & 41,529 & 0.659 & 0.474 & 0 & 1 \\
\hline Youth LFP & 36,544 & 0.574 & 0.494 & 0 & 1 \\
\hline Geographical mobility & 31,881 & 0.119 & 0.324 & 0 & 1 \\
\hline Living at home & 31,881 & 0.410 & 0.492 & 0 & 1 \\
\hline Family size & 118,914 & 2.942 & 1.722 & 1 & 16 \\
\hline Age & 118,914 & 47.692 & 23.070 & 15 & 90 \\
\hline Up to 12 years of school & 118,914 & 0.571 & 0.495 & 0 & 1 \\
\hline Some college & 118,914 & 0.238 & 0.426 & 0 & 1 \\
\hline Married & 118,914 & 0.475 & 0.499 & 0 & 1 \\
\hline Divorced & 118,914 & 0.085 & 0.278 & 0 & 1 \\
\hline Real income & 118,914 & 48,727 & 49,198 & -16114 & 763,699 \\
\hline
\end{tabular}

Table A4 American Time Use Survey, 2003-2008, summary statistics

\begin{tabular}{|c|c|c|c|c|c|}
\hline Variable & Observations & Mean & SD & Min & Max \\
\hline Home production & 3,290 & 123.45 & 139.69 & 0 & 1,015 \\
\hline Age & 3,290 & 49.23 & 22.29 & 15 & 85 \\
\hline Family income & 3,290 & 9.93 & 3.93 & 1 & 16 \\
\hline Less than high school & 3,290 & 0.22 & 0.41 & 0 & 1 \\
\hline High school & 3,290 & 0.26 & 0.44 & 0 & 1 \\
\hline Married & 3,290 & 0.44 & 0.50 & 0 & 1 \\
\hline Employed & 3,290 & 0.50 & 0.50 & 0 & 1 \\
\hline
\end{tabular}




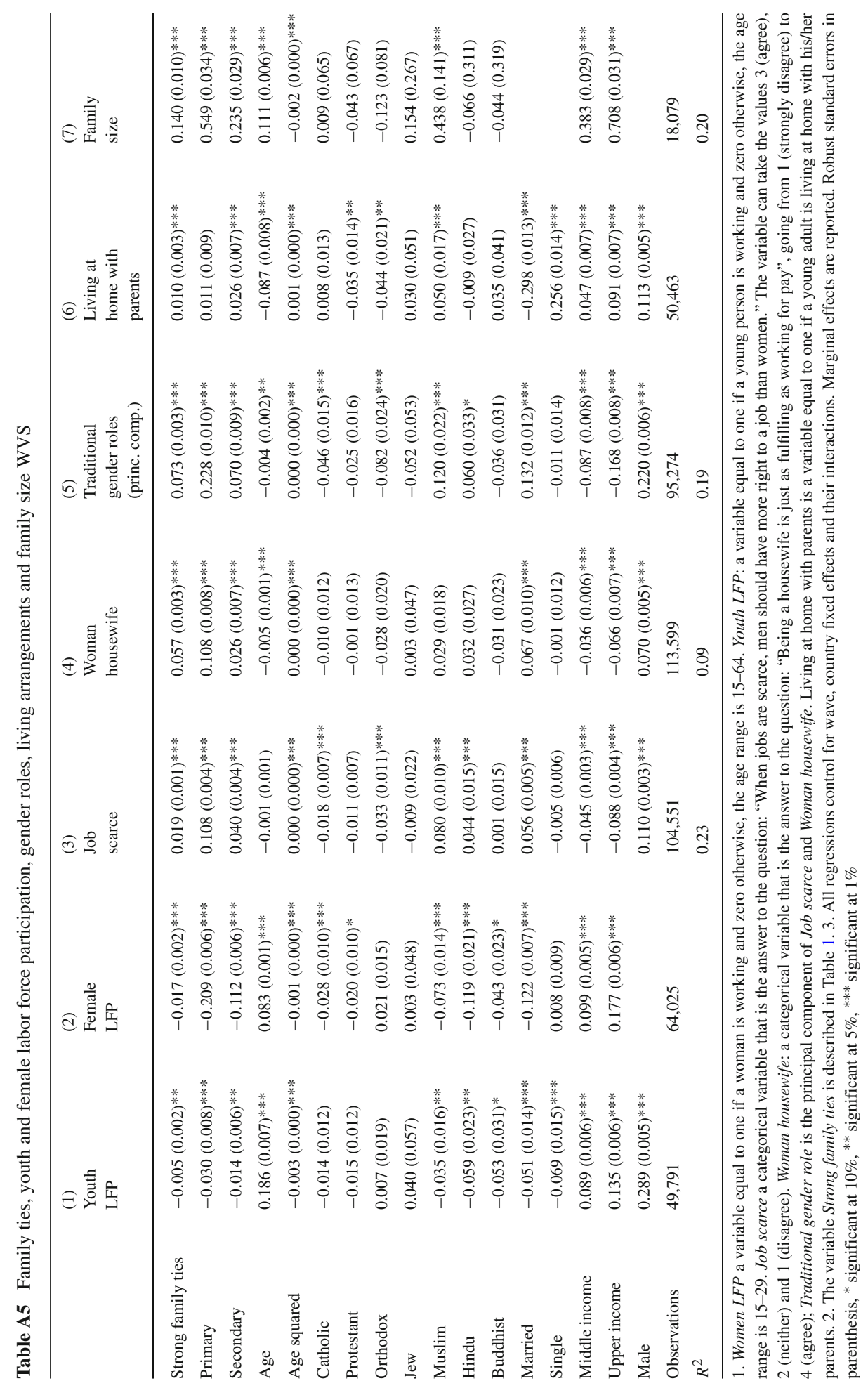




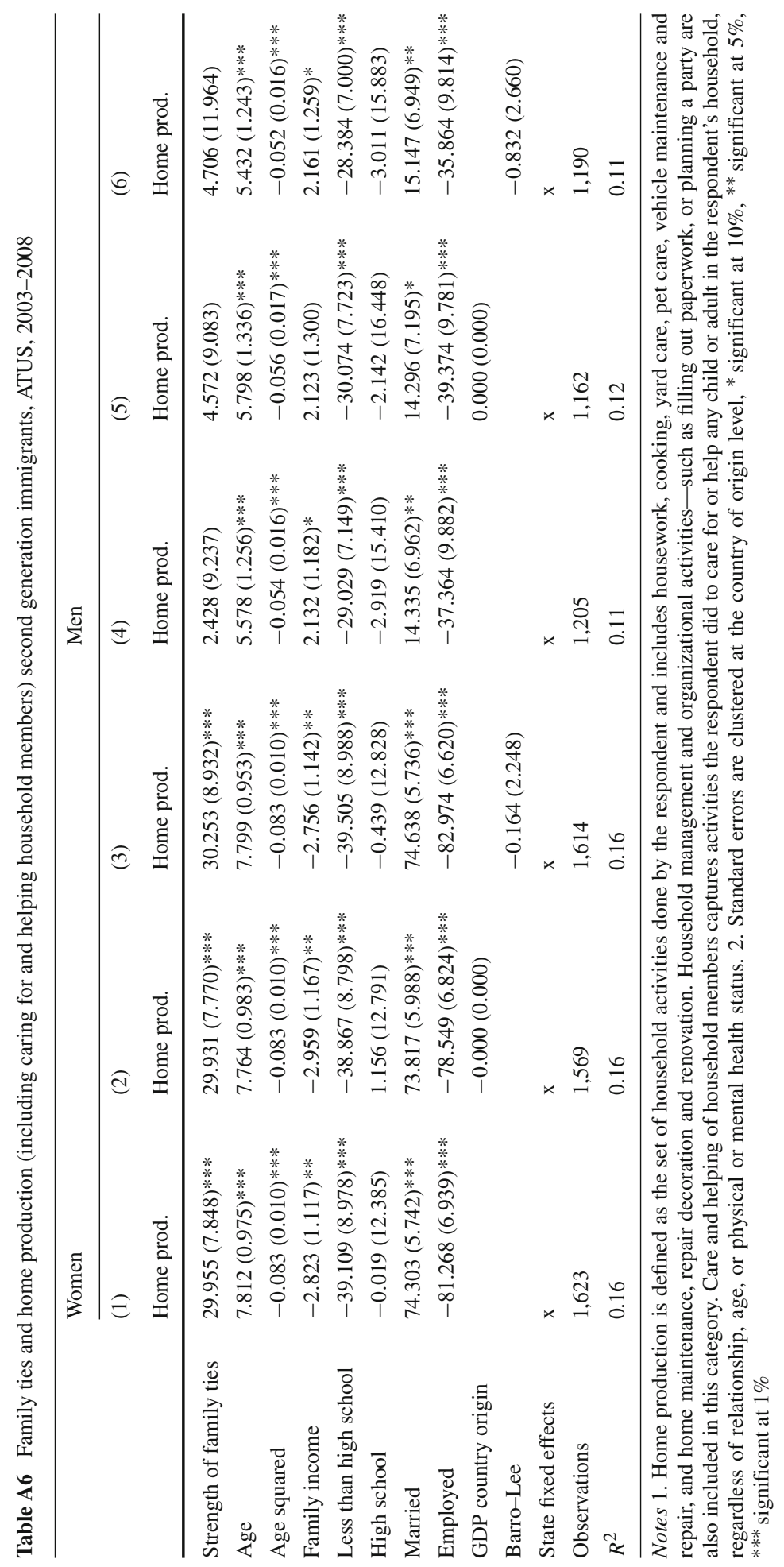


Table A7 Family ties and economic outcomes of second generation immigrants Evidence from the European Social Survey

\begin{tabular}{llll}
\hline & $(1)$ & $(2)$ & $(3)$ \\
& Youth LFP & Female LFP & Family size \\
\hline Strength of family ties & $-0.087(0.052)^{*}$ & $-0.029(0.033)$ & $0.138(0.072)^{*}$ \\
Age & $0.256(0.045)^{* * *}$ & $0.081(0.005)^{* * *}$ & $0.004(0.005)$ \\
Age squared & $-0.004(0.001)^{* * *}$ & $-0.001(0.000)^{* * *}$ & $-0.000(0.000)^{* * *}$ \\
Primary & $-0.048(0.068)$ & $-0.268(0.034)^{* * *}$ & $-0.065(0.077)$ \\
Secondary & $-0.078(0.037)^{* *}$ & $-0.128(0.022)^{* * *}$ & $0.157(0.049)^{* * *}$ \\
Married & $-0.089(0.050)^{*}$ & $-0.086(0.026)^{* * *}$ & \\
Single & $-0.015(0.034)$ & $0.093(0.033)^{* * *}$ & \\
Female & $-0.118(0.028)^{* * *}$ & & \\
Country of destination f.e. & $\mathrm{x}$ & $\mathrm{x}$ & $\mathrm{x}$ \\
Observations & 1,359 & 2,372 & 5,332 \\
$R^{2}$ & & & 0.10
\end{tabular}

Data on second generation immigrants are taken from the 2004 and 2006 wave of the European Social Survey. The European Social Survey includes 27 countries: Austria, Belgium, Bulgaria, Switzerland, Cyprus, Czech Republic, Germany, Denmark, Estonia, Spain, Finland, France, Great Britain, Greece, Hungary, Ireland, Iceland, Luxembourg, Netherlands, Norway, Poland, Portugal, Sweden, Slovenia, Slovak Republic, Turkey, Ukraine 


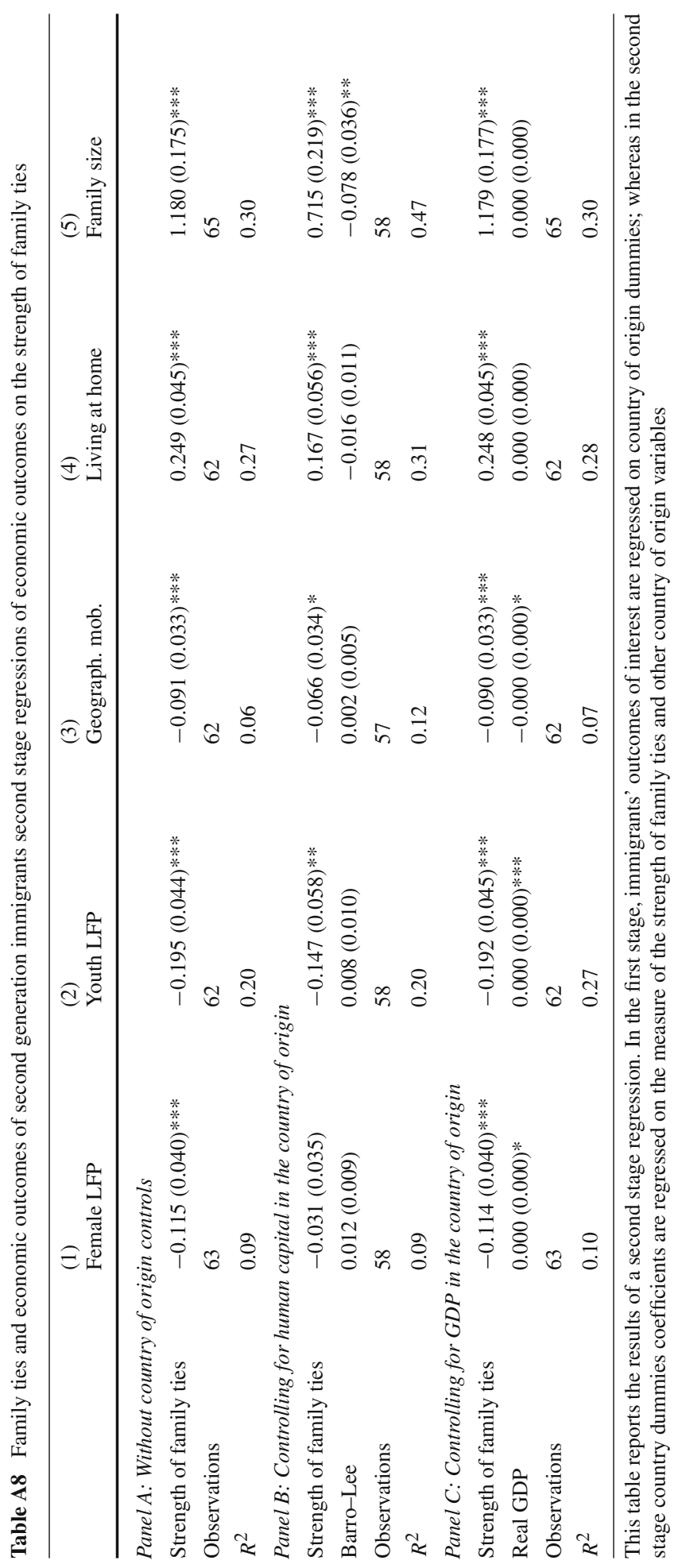




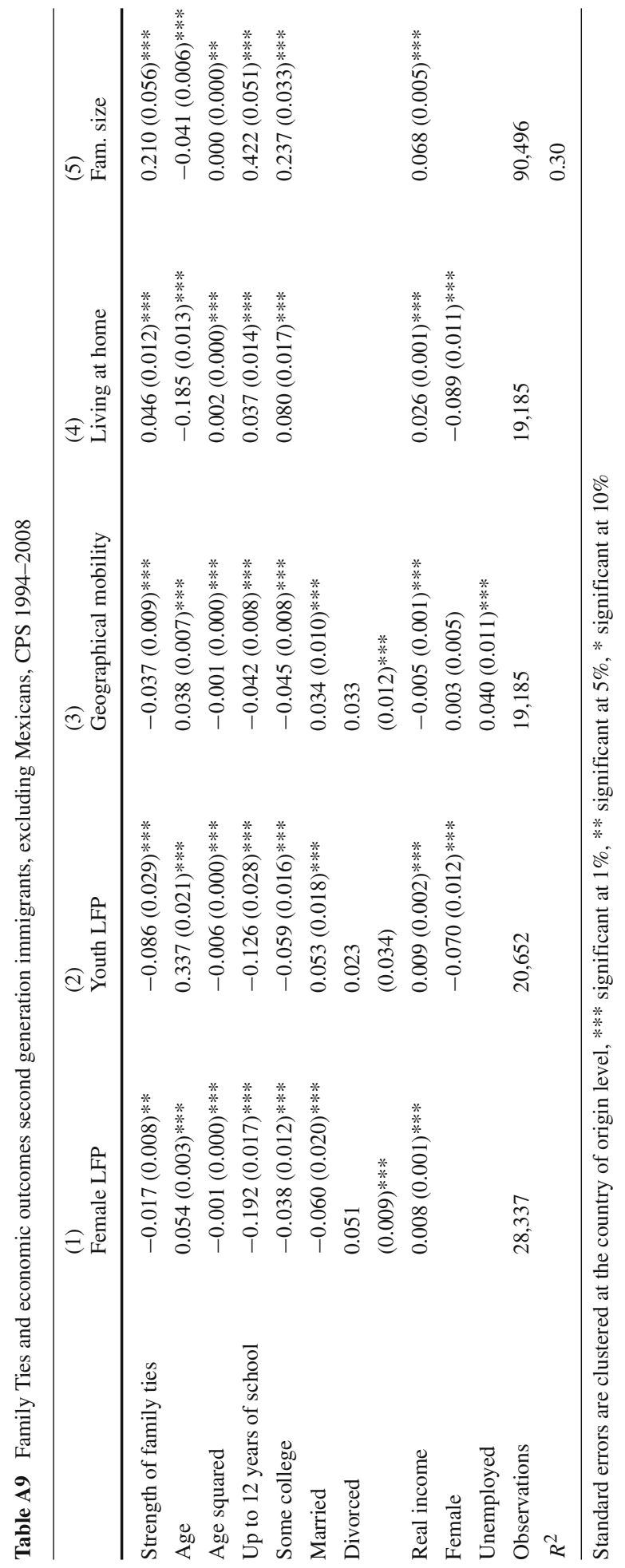




\section{References}

Alesina, A. F., Glaeser, E. L., \& Sacerdote, B. (2005). Work and leisure in the United States and Europe: Why so different? NBER Macroeconomic Annual, 20, 1-64.

Algan, Y., \& Cahuc, P. (2007). The roots of low European Employment: Family culture?. In J. Frenkel \& C. Pissarides (Eds.), NBER Macroeconomic Annual. Cambridge, MA: MIT Press.

Algan, Y., \& Cahuc, P. (2010). Inherited trust and growth. American Economic Review (forthcoming).

Antecol, H. (2000). An examination of cross-country differences in the gender gap in labor force participation rates. Labour Economics, 7, 409-426.

Banfield, E. C. (1958). The moral basis of a backward society. New York: The Free Press.

Barro, R., \& Lee, J. W. (2001). International data on educational attainment: Updates and implications. Oxford Economic Papers, 53, 541-563.

Bartel, A. (1979). The migration decision: What role does job mobility play?. American Economic Review, 69, 775-786.

Benabou, R., \& Tirole, J. (2006). Beliefs in a just world and redistributive politics. Quarterly Journal of Economics, 121(2), 699-746.

Bentolila, S., \& Ichino, A. (2008). Unemployment and consumption near and far away from the mediterranean. Journal of Population Economics, 21, 255-280.

Bertrand, M., \& Schoar, A. (2006). The role of family in family firms. Journal of Economic Perspectives, 20(Spring), 73-96.

Bisin, A., Topa, G., \& Verdier, T. (2004). Cooperation as a transmitted cultural trait. Rationality and Society, 16, 477-507.

Bisin, A., \& Verdier, T. (2000). Beyond the melting pot: Cultural transmission, marriage and the evolution of ethnic and religious traits. Quarterly Journal of Economics, 115(3), 955-988.

Bisin, A., \& Verdier, T. (2001). The economics of cultural transmission and the evolution of preferences. Journal of Economic Theory, 97(2), 298-319.

Blanchard, O. (2004). The economic future of Europe. Journal of Economic Perspectives, 18(4), 3-26.

Blanchard, O., \& Katz, L. (1992). Regional evolutions. Brookings Papers on Economic Activity, 1, 1-61.

Borjas, G. (1992). Ethnic capital and intergenerational mobility. Quarterly Journal of Economics, 107(1), $123-150$.

Borjas, G. (1995). Ethnicity, neighborhoods, and human-capital externalities. American Economic Review, 85(3), 365-390.

Card, D., DiNardo, J., \& Estes, E. (1998). The more things change: Immigrants and the children of immigrants in the 1940s, the 1970s, the 1990s. NBER Working Paper 6519.

Carroll, D., Rhee, B., \& Rhee, C. (1994). Are there cultural effects on saving? Some cross-sectional evidence. Quarterly Journal of Economics, 109(3), 685-700.

Castles, F. (1995). Welfare State Development in Southern Europe. Western European Politics, 18, $201-213$.

DaVanzo, J. (1978). Does unemployment affect migration? Evidence from micro data. Review of Economics and Statistics, 6, 504-514.

Esping-Andersen, G. (1999). Social foundation of post-industrial economies. Oxford: Oxford University Press.

Faggio, G., \& Nickell, S. (2006). Patterns of work across the OECD. CEP Discussion Paper No. 730.

Fernandez, R., \& Fogli, A. (2009). Culture: An empirical investigation of beliefs, work and fertility. American Economic Journal: Macroeconomics, 1(1), 146-177.

Ferrera, M. (1996). The southern model of welfare in social Europe. Journal of the European Social Policy, 1, 17-37.

Giuliano, P. (2007). Living arrangements in Western Europe: Does cultural origin matter?. Journal of the European Economic Association, 5(5), 927-952.

Giuliano, P. (2010). Ties that matter: Cultural norms and family formation in Western Europe. In C. Brown, B. Eichengreen, \& M. Reich (Eds.), Labor in the era of globalization. Cambridge: Cambridge University Press.

Guiso, L., Sapienza, P., \& Zingales, L. (2003). People's Opium? Religion and economic attitudes. Journal of Monetary Economics, 50, 225-282.

Guiso, L., Sapienza, P., \& Zingales, L. (2006). Does culture affect economic outcomes? Journal of Economic Perspectives, 20(Spring), 23-48.

Hammermesh, B. M. D., \& Weil, P. (2006). Different but equal: Total work, gender and social norms in EU and US time use. Mimeo

Inglehart, R., \& Baker, W. (2000). Modernization, cultural change and the persistent of traditional values. American Sociological Review, 65, 19-51. 
Jaumotte, F. (2003). Female labour force participation: Past trends and main determinants in OECD countries. OECD Economics Department WP 376.

Korpi, W. (2000). Faces of inequality: Gender, class and patterns of inequalities in different types of welfare states. Social Politics, 7, 127-191.

Luttmer, E. (2001). Group loyalty and the taste for redistribution. Journal of Political Economy, 109(3), 500-528.

Luttmer, E., \& Singhal, M. (2008). Culture, context and the taste for redistribution. NBER WP 14268.

Pissarides, C., \& Wadsworth, J. (1989). Unemployment and the inter-regional mobility of labour. Economic Journal, 99, 739-755.

Prescott, E. (2004). Why do Americans work so much more than Europeans? Federal Reserve of Minneapolis Quarterly Review, 28, 2-13.

Reher, D. (1998). Family ties in Western Europe: Persistent contrasts. Population and Development Review, XXIV, 203-234.

Schwartz, S., Bardi, A., \& Bianchi, G. (2000). Values adaptation to the imposition and collapse of communist regimes in east-Central Europe. In S. A. Renshon \& J. Duckitt (Eds.), Political psychology: Cultural and cross-cultural foundations. New York: New York University Press.

Tabellini, G. (2008). The scope of cooperation: Values and incentives. Quarterly Journal of Economics, 123(3), 905-950.

Tabellini, G. (2010). Culture and institutions: Economic development in the regions of Europe. Journal of the European Economic Association, 8(4), 677-716. 